\title{
OPTIMISATION OF THIN AND THICK FILM TECHNOLOGY FOR HYBRID MICROWAVE CIRCUITS
}

\author{
HOLGER MEINEL, BERNHARD REMBOLD and WERNER WIESBECK \\ AEG-Telefunken Nachrichten- und Verkehrstechnik $A G$ \\ Geschaftsbereich Hochfrequenztechnik Elisabethenstr. 3 D 7900 Ulm, Donau, West Germany
}

(Received June 1, 1977)

In the last ten to fifteen years the development of microstrip techniques has made a great step forward. After the first theoretical analyses given during the early fifties, ${ }^{1-3}$ investigations about field distribution, mode conditions and dispersion characteristics were carried out with great success. ${ }^{4-15}$ One could say that the theoretical treatment of microstrip is almost complete.

Nearly all components formerly built in waveguideor coaxial-technique, for example, oscillators, mixers, directional couplers, and filters, even entire units like doppler radar modules are now being built, using microstrip technique.

There are several different methods of realizing microstrip circuits. Each technology, e.g. thinfilm, thickfilm, has its own advantages and disadvantages for hybrid microwave technology. This can be in costs, reliability, $Q$-factor or other special requirements.

Three special technologies should be compared in regard to their application for microwave circuits: thickfilm, thinfilm, chemical metallisation (CMS). Most of the features that are necessary for lower frequencies, like surface flatness or edge accuracy, apply in the microwave field as well. The most critical additional demand is that of low losses. The origin of losses are the loss tangent of the substrate material, conductor losses, surface roughness and high surface current density of the strip due to the strip manufacturing process as well as adhesion layers with poor electrical performance. Radiation losses must also be regarded.

Dielectric losses are determined by the choice of the substrate material. In order to show the importance of this choice for the resulting technical performance of the hybrid device, especially for the frequency range up to $16 \mathrm{GHz}$, Figure 1 presents a

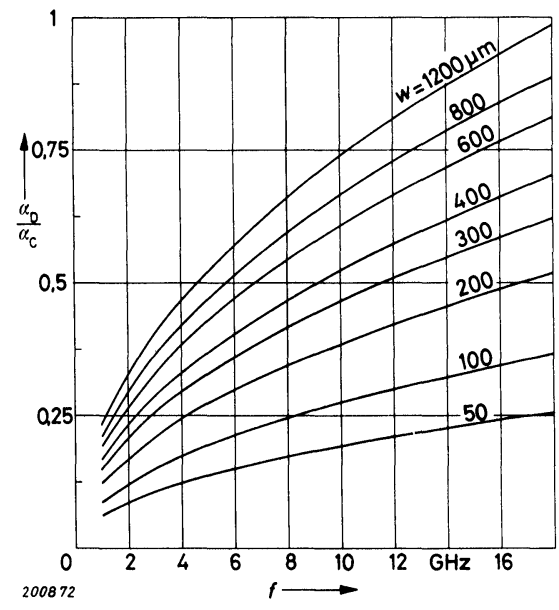

FIGURE 1 Dielectric to ohmic attenuation ratio with frequency ( $t=8$ skindepths).

comparison between dielectric and ohmic losses as a function of frequency. Considering a $50 \Omega$ microstrip line, it can be seen that, for frequencies above $6 \mathrm{GHz}$, line attenuation is mainly caused by dielectric losses. Below $6 \mathrm{GHz}$ ohmic loss is the main reason for attenuation. Because of the square law dependence of these losses on the surface current density it is necessary to know the current distribution on a microstrip-line. Figure 2 presents the unrolledsurface current of a $50 \Omega$ microstrip line in propagation direction. At the strip edges the current density reaches the highest value, whereas in the center the lowest value is obtained. Further it can be seen, that the maximum value increases, if the edge radius becomes smaller. That means, giving the strip cross-section a special shape, will lower the current density at the strip edges, resulting in a 


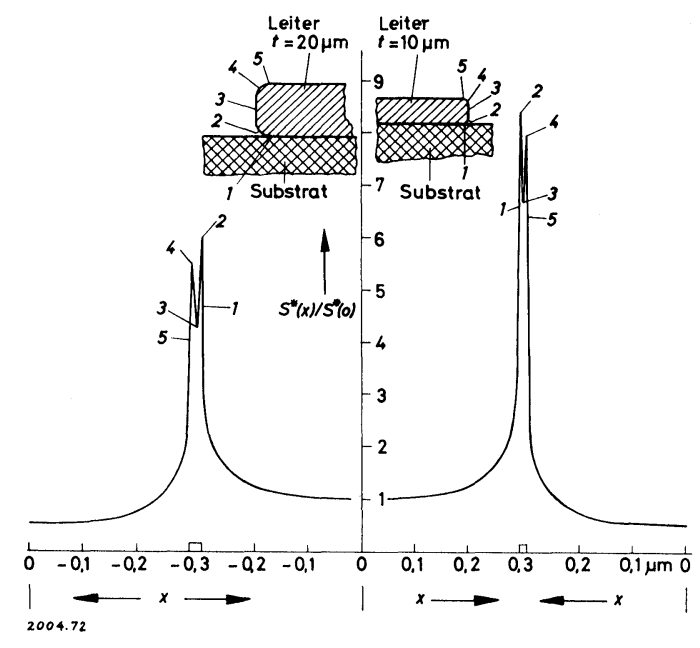

FIGURE 2 Surface current density on the strip.

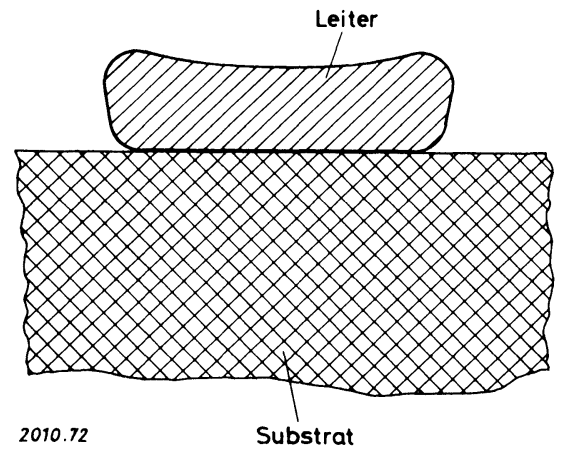

FIGURE 3 Optimum shape of cross-section for a microstrip line.

decrease of the ohmic losses. The computer optimised shape of the strip cross-section, Figure 3, has rounded corners instead of sharp edges. Such a geometry is obtained by the normal thinfilm production process. Under-etching with following electroplating leads to the required strip crosssection. A practical result is presented in Figure 4; the subtractive CMS process followed by electroplating was used in the manufacture of the microstrip-line.

Another important point for the optimum design of microstrip circuits concerns the loss distribution on the strip. Figure 5 presents the ratio of the losses due to the ground plane currents to the entire ohmic losses as a function of strip-width. It can be seen, that for a $50 \Omega$ line on a $0.635 \mathrm{~mm}$ alumina substrate the amount of the ground plane losses is only $15 \%$ of the entire ohmic losses, i.e. the ground plane

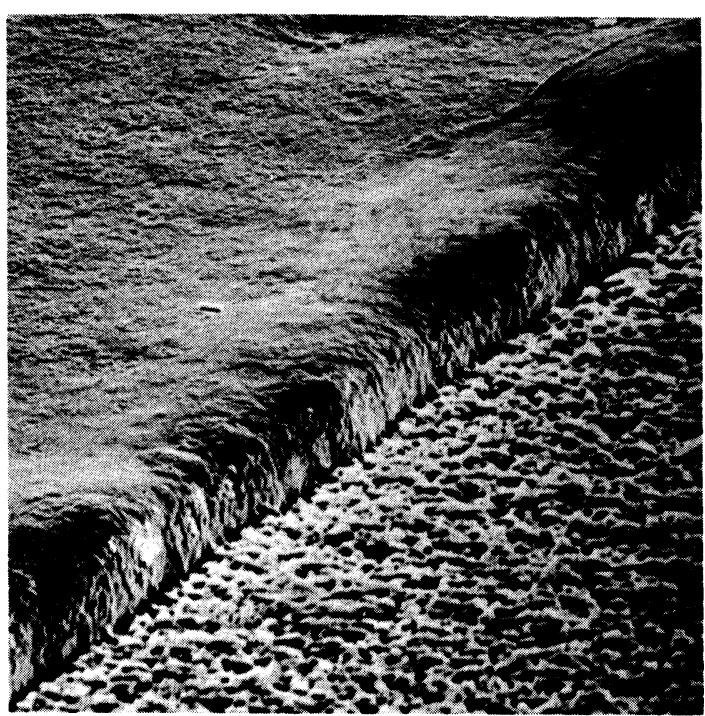

FIGURE 4 Edge of a microstrip line realized by subtractive CMS-processing with following electroplating. (Length of bottom edge, $20 \mu \mathrm{m}$ ).

metallisation can be carried out using a material with low conductivity.

Conductivity, the main reason for ohmic losses, is virtually fixed by the material being used. In order to compare the various conductor materials and the different technology procedures attenuation measurements were carried out. Using microstrip ring-resonators the $Q$-factor can be determined. ${ }^{16}$ The following equation relates $Q$-factor and

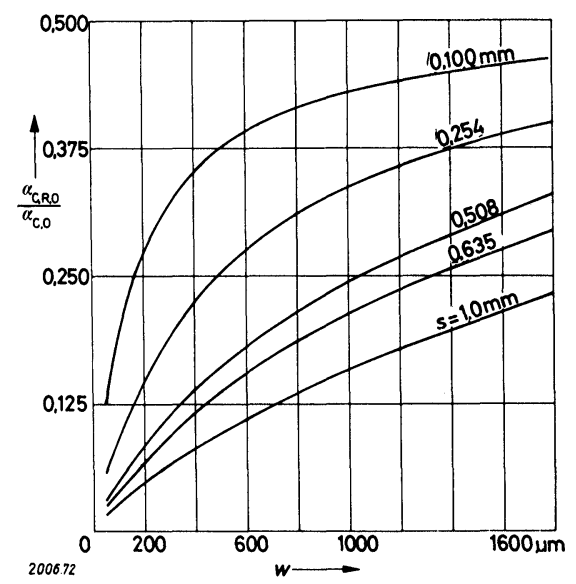

FIGURE 5 Ratio of attenuation caused by ground plane losses and ohmic losses respectively as a function of stripwidth $w .(t=8$ skindepths $)$. 
attenuation

$$
\begin{aligned}
& \alpha=\frac{\pi}{Q \lambda} \\
& \alpha=\text { attenuation coefficient in } N p \text { per } \\
& \text { length-unit } \\
& \lambda=\text { line wavelength }
\end{aligned}
$$

$Q$-factor measurements, employing a network analyzer have been made between 1 and $16 \mathrm{GHz}$. Figure 6 shows the result for various materials and different technologies as a function of frequency.

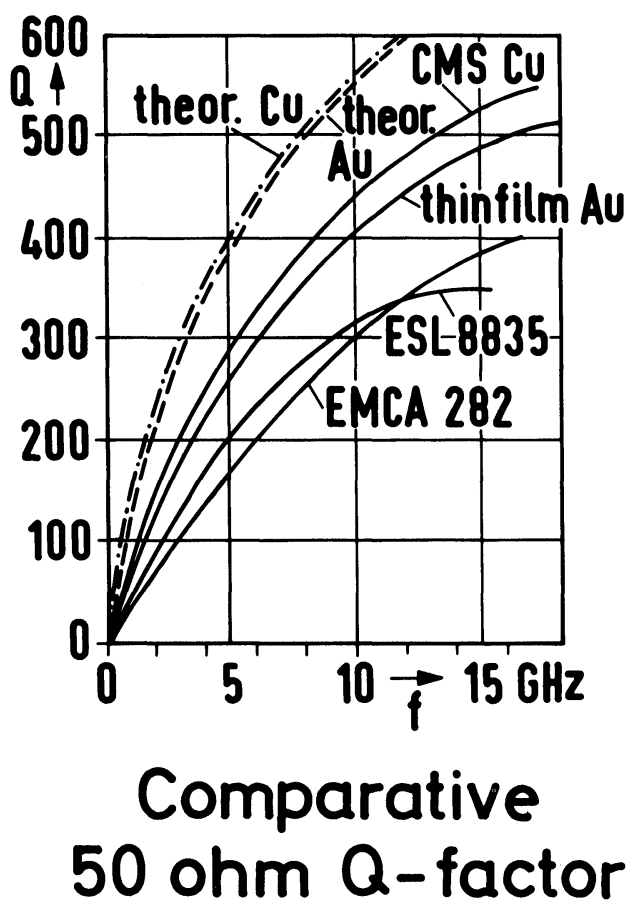

FIGURE $6 \quad 50 \mathrm{Ohm} Q$-factor.

The CMS-procedure, a galvanic metallisation process, developed at AEG-TELEFUNKEN, shows the best result. A microstrip-line, manufactured using this procedure is presented in Figure 4. The strip shows very low surface roughness and good edge accuracy.

Thinfilm technique using vacuum evaporation or sputtering with gold conductors has a similar frequency dependence. The $Q$-factor is only slightly lower. A microstrip-line manufactured using this technique is presented in Figure 7. It also has a low surface roughness and good edge accuracy. Thickfilm technique, using screen printing, leads to lower

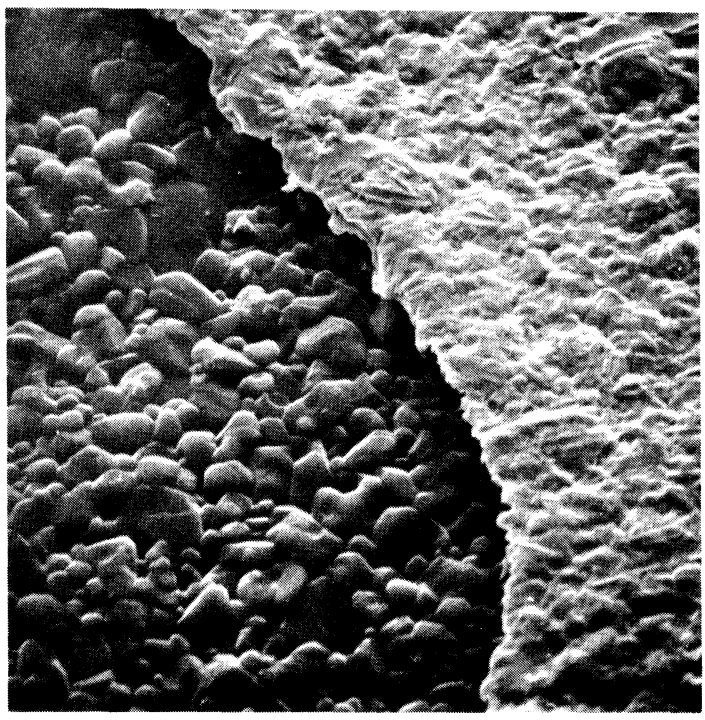

FIGURE 7 Edge of a microstrip line realized by thin film processing. (Length of bottom edge, $50 \mu \mathrm{m}$ ).

$Q$-factor values, with a frequency dependence, due to the material being used. Thickfilm manufactured microstrip-lines are presented in Figure 8 and 9.

Figure 8 shows a line, which was printed, using ESL 8835 , a material with normal glass content. Very bad edge accuracy, but only low surface roughness can be seen. This is in good agreement with the measured $Q$-factor; a relatively high $Q$-factor value below $6 \mathrm{GHz}$

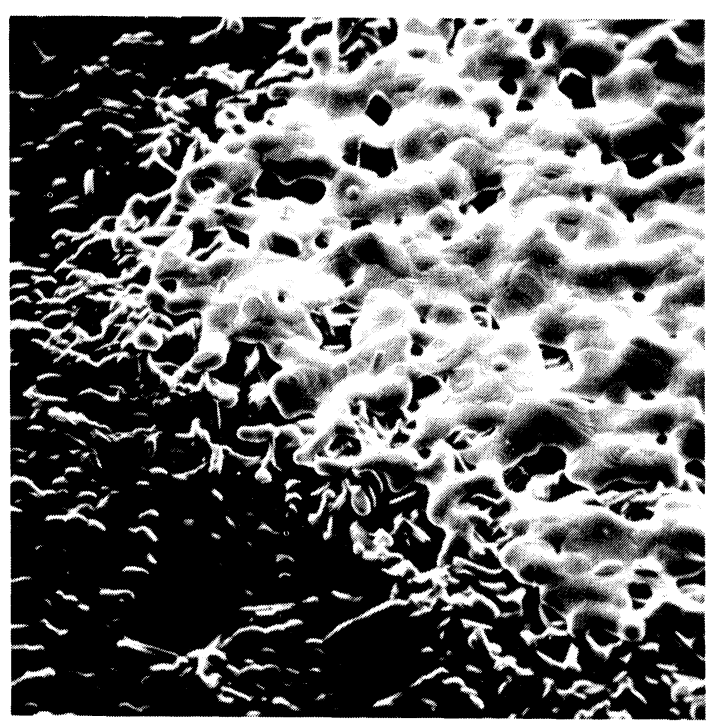

FIGURE 8 Edge of microstrip line realized by thick film processing. (Conductor material ESL 8835). (Length of bottom edge, $110 \mu \mathrm{m})$. 


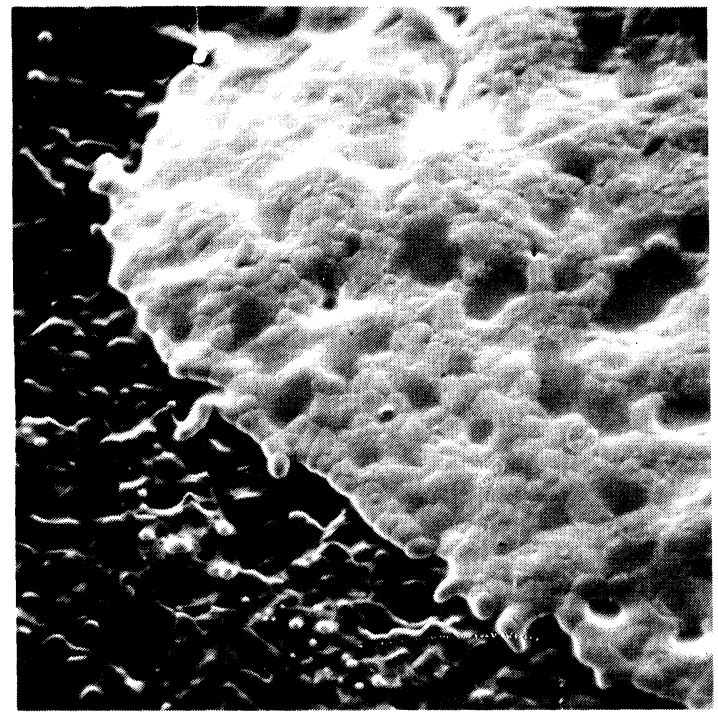

FIGURE 9 Edge of a microstrip line realized by thick film processing. (Conductor material EMCA 282). (Length of bottom edge, $105 \mu \mathrm{m})$.

and a comparatively low value for higher frequencies due to the roughness of the edges can be achieved. EMCA 282 was used to make the line shown in Figure 9. This is a material with a very high gold content, i.e. nearly fritless. Now good edge accuracy can be achieved, but the surface roughness is increased. Once more the good agreement with the $Q$-factor measurements can be seen. For frequencies below $8 \mathrm{GHz}$ the $Q$-factor is lowered because of the higher surface roughness.

All the presented technologies have their advantages and disadvantages. In thinfilm- or CMStechnique it is possible to produce microstrip-lines with good accuracy, especially for higher frequencies, but it is impossible to build line-crossings, as is possible using thickfilm technique. Thinfilm resistors are not suitable for microwave hybrid circuits because

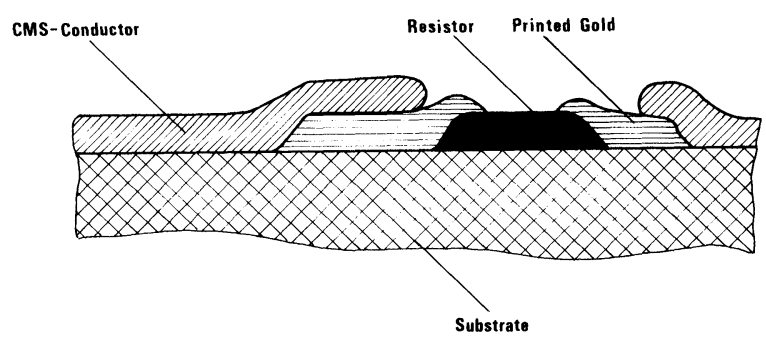

FIGURE 10 Cross-section of a compound hybrid layer. of their high inductivity. Thickfilm technique gives very good microwave resistors. This lead to the development of the compound layer technique at AEG-TELEFUNKEN, which retains the advantages of both techniques without the disadvantages. Figure 10 presents the cross-section of a compound layer hybrid circuit.

\section{REFERENCES}

1. F. Assadourian and E. Rimai, "Simplified theory of microstrip transmission systems," Proc. of IRE, Vol. 40, 12, p. 1651-1657.

2. G. A. Deschamps, "Theoretical aspects of microstrip waveguide," IRE Trans. Vol. MTT-2, 2, (1954), p. 100 102.

3. K. G. Black and T. J. Higgins, "Rigorous determination of the parameters of microstrip transmission lines," IRE Trans, Vol. MTT-3, 2, (1955), p. 93-113.

4. H. A. Wheeler, "Transmission-line properties of parallel wide strips by a conformalmapping approximation," IEEE Trans. Microwave Theory and Techniques, MTT-12, (1964), 280-289.

5. H. A. Wheeler, "Transmission-line properties of parallel strips separated by a dielectric sheet," IEEE Trans. Microwave Theory and Techniques, MTT-13, (1965), $172-185$.

6. E. Yamashita, "A variational method for the analysis of microstrip like Transmission-lines," IEEE Trans. Vol. $M T T-16,8,(1968)$, p. 529-535.

7. E. J. Denlinger, "A Dynamic TE-TM mode solution for microstrip," Pres. at 1964 G-MTT Symposium, (May 1969).

8. R. E. Cooke, "Dispersion characteristics of microstrip transmission lines presented at 1969 Europ. Microw. Symp. Session A1," (Sept. 1969).

9. W. Wiesbeck, "Berechnung der Dämpfung ungeschirmte Streifenleitungen." Wiss, Berichte AEG-Telefunken, 45, (1972), S. 162-166.

10. W. Wiesbeck, "Berechnung und Messung der Stromverteilung auf ungeschirmten Streifenleitungen," $N T Z$, 25, (1972), 1-6.

11. R. A. Pucel, D. J. Masse, C. P. Hartwig, "Losses in micro strip," Trans. IEEE Microwave Theory and Techniques, $M T T-16$, (1968), 342-350. Correction: p. 1064.

12. M. V. Schneider, "Dielectric loss in integrated microwav circuits," Bell Syst. Techn. J., 48, (1969), 2325-2332.

13. G. Kowalski, R. Pregla, "Dispersion characteristics of shielded microstrips with finite thickness," $A E \ddot{U}, 25$, (1971), 193-196.

14. W. J. Chudobiak, O. P. Jain, V. Makios, "Dispersion in microstrip," IEEE Trans. Microwave Theory and Techniques, $M T T-19$, (1971), 783-784.

15. M. V. Schneider, "Microstrip dispersion," Proc. IEEE, 60, (1972), 144-146.

16. H. Groll, W. Berghofer, "Zur Messung des Gütefaktors von Mikrowellenresonatoren," NTZ, 22, (1969), S. 216-220. 

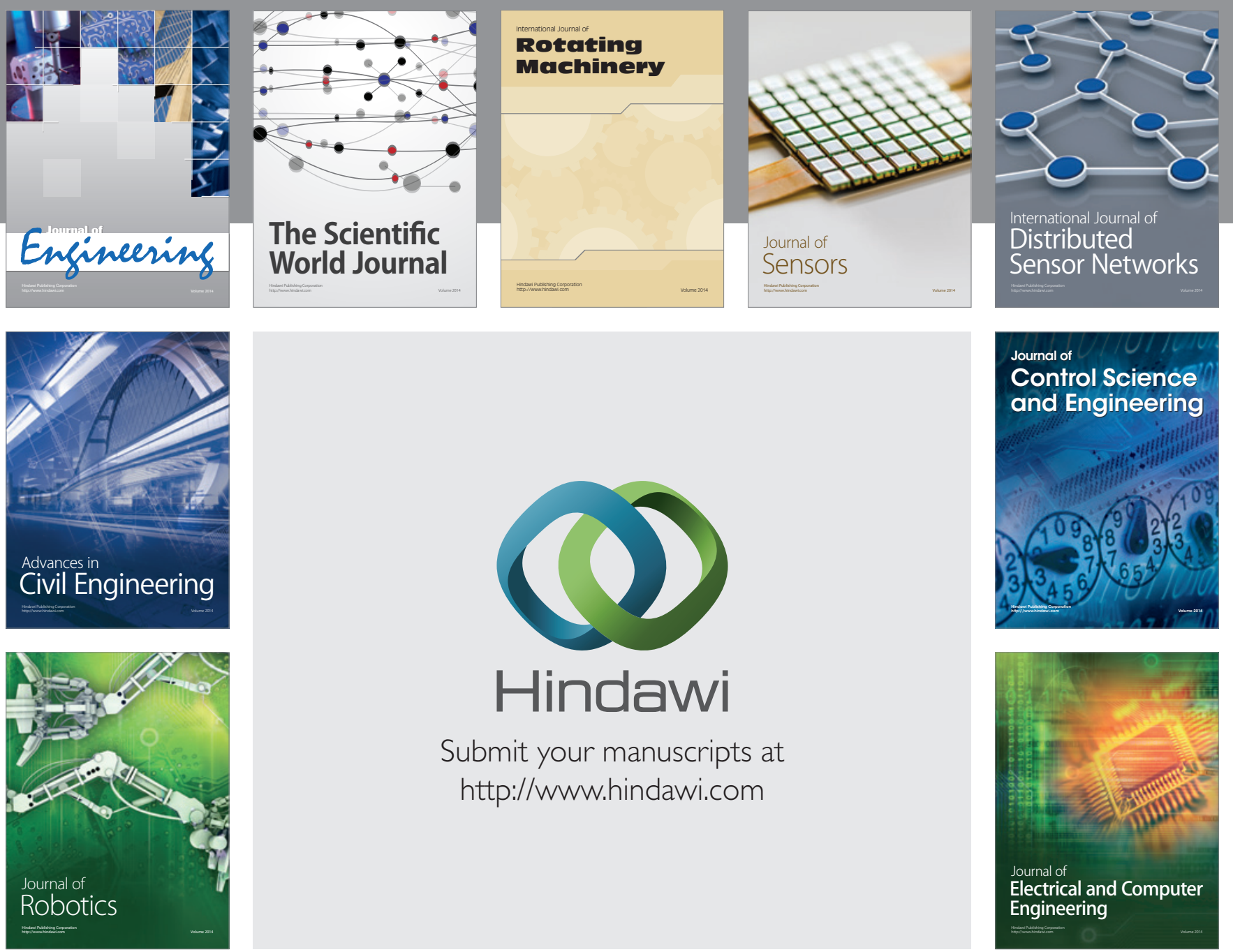

Submit your manuscripts at

http://www.hindawi.com
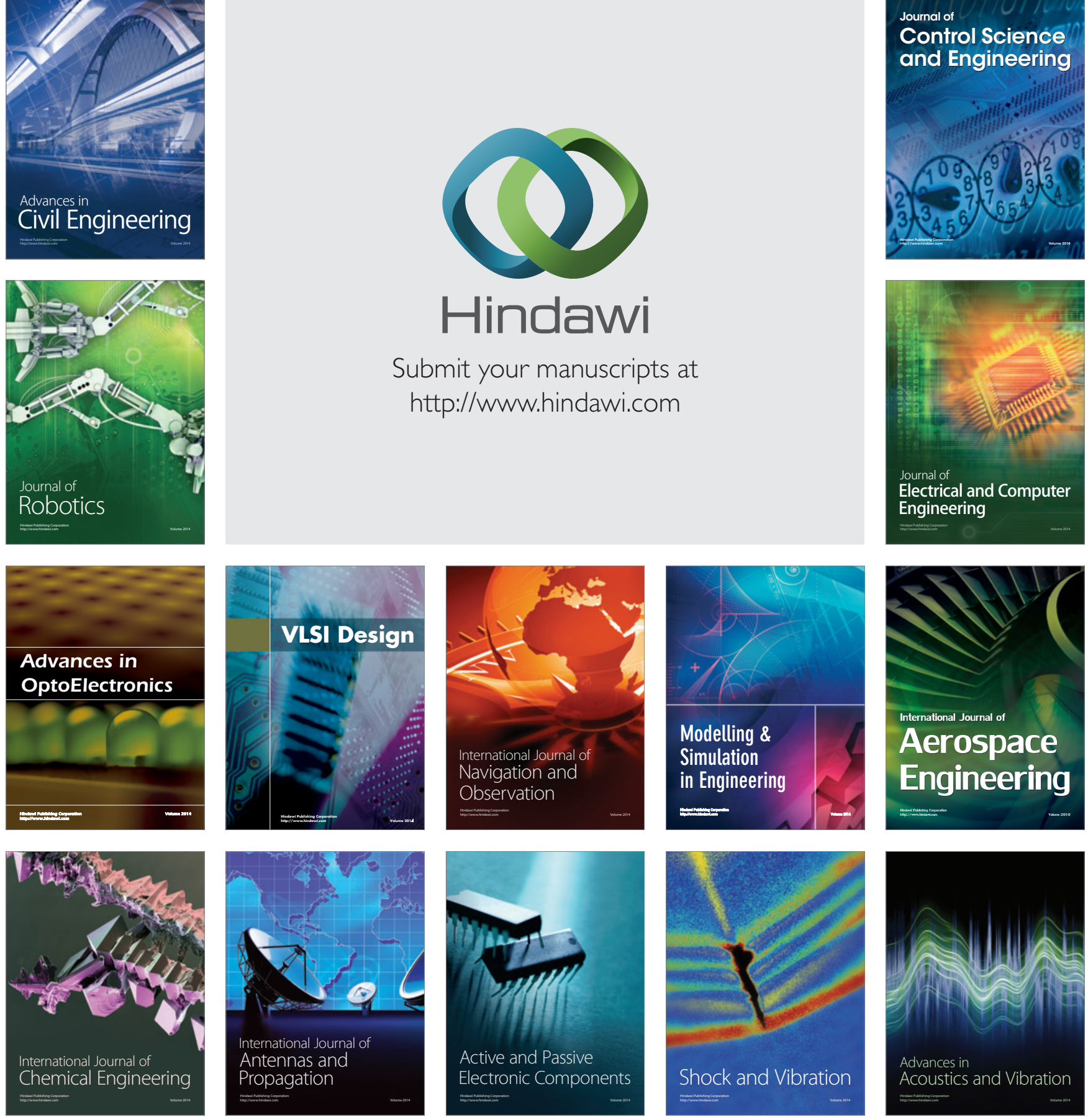